\title{
Optimization of Polymer Processing: A Review (Part II- Molding Technologies)
}

\author{
António Gaspar-Cunha ${ }^{1 *}$, José A. Covas ${ }^{1}$ and Janusz Sikora ${ }^{3}$ \\ 1 Institute of Polymers and Composites, University of Minho, agc@dep.uminho.pt, jcovas@dep.uminho.pt \\ 2 Institute of Polymers and Composites, University of Minho, jcovas@dep.uminho.pt \\ 3 Department of Technology and Polymer Processing, Faculty of Mechanical Engineering, Lublin University \\ of Technology, Nadbystrzycka 36, 20-618 Lublin, Poland, janusz.sikora@pollub.pl \\ * Correspondence: agc@dep.uminho.pt; Dept. of Polymer Engineering, Campus de Azurém, University of \\ Minho, Guimarães, Portugal
}

\begin{abstract}
The application of optimization techniques to improve the performance of polymer processing technologies is of great practical consequence, since it may result in significant savings of materials and energy resources, assist recycling schemes and generate products with better properties. The present review aims at identifying and discussing the most important characteristics of polymer processing optimization problems in terms of the nature of the objective function, optimization algorithm, and process modelling approach that is used to evaluate the solutions and the parameters to optimize. Taking into account the research efforts developed so far, it is shown that several optimization methodologies can be applied to polymer processing with good results, without demanding important computational requirements. Also, within the field of artificial intelligence, several approaches can be reach significant success. The first part of this review demonstrated the advantages of the optimization approach in polymer processing, discussed some concepts on multi-objective optimization and reported the application of optimization methodologies in single and twin screw extruders, extrusion dies and calibrators. This second part focus on injection molding, blow molding and thermoforming technologies.
\end{abstract}

Keywords: polymer processing, single screw, twin screw, injection molding, blow molding, thermoforming, optimization, artificial intelligence

\section{Introduction}

Societal and economic requirements, as well as environmental sustainability policies, progressively call for manufacturing technologies that consume less resources, yield more performing products, and accept bio-friendly materials, even if these often have inferior properties. Given the current worldwide concern with the environmental impact of plastics, there is certainly an impetus towards increasing the performance of polymer processing technologies.

Processing of thermoplastic polymers typically comprises a plasticizing step, followed by melt shaping and cooling. These steps have been extensively analyzed both experimentally and phenomenologically in terms of fluid mechanics, heat and mass transfer, rheology, solid mechanics, polymer physics and chemistry. Physical models, and subsequently mathematical descriptions of the processes, have been used to develop computational modelling routines, which are gradually able to determine with good accuracy the behavior of the various processing routines for specific sets of equipment geometry, operating conditions and material properties [1-4].

In part 1 of this work [5] it was shown that the available process modelling routines are often used inefficiently to solve real processing problems, such as setting the operating conditions of a process, define the profile of a plasticizing screw, balance the runner system of an injection mold, define the geometry of the pre-form for blowing a bottle with a 
specific thickness profile, or identify the temperature distribution of a sheet for thermoforming a part with a given thickness gradient. Indeed, these powerful simulation tools are frequently exploited on a trial and error basis, requiring from the user the capacity to assess the suitability of each process response and input a better one. Therefore, the authors advocated the formulation of real processing problems as optimization problems.

As depicted in Figure 1, the optimization approach involves modelling and optimization routines, and routines able to deal with the articulation of the objectives of the optimization. The process modelling routine must be able to handle the decision variables (typically operating conditions and/or geometric parameters) in order to obtain measures of performance (objectives and restrictions). Since most polymer processing problems are multi-objective and multi-constrained $[6,7]$, there is a need to consider the simultaneous existence of several objectives and constraints. Thus, the objectives routines must deal with the objectives in such a way that the optimization routines understand, i.e., rank the solutions using a single number. In turn, the optimization algorithms decide about the solutions to be evaluated by the modelling routine, i.e., they define the sets of decision variables to be passed to the modelling routine. This decision is made on the basis of the performance measures of the previous evaluated solution.

Other, often more complex relationships must be also established between the existing and/or generated data and the decision variables, objectives, constraints and environmental parameters (see Figure 1):

i) data are generated experimentally and/or computationally. For a given problem, data maybe created either while the machine is operating (on-line), or disconnected from the process (off-line) and environmental data may eventually influence the process (e.g., room temperature, humidity). A global and complete portrait of the process can be built applying, for example, data mining techniques, in order to establish relations between the data, including necessarily objectives and constraints. This type of analysis relies on the use of Artificial Intelligent (AI) models that are able to tackle the decisions about the process;

ii) the use of environmental data may contribute to obtaining robust solutions, i.e., solutions that perform well for a range of variation of specific design variables. For instance, if the room temperature influences the performance of a specific process, a robustness analysis can be made in order to find a better solution performing satisfactorily under a wider range of room temperatures;

iii) the multi-objective nature of the problems needs to be considered in a sophisticated way, since the use of simple methods, such as the aggregated sum, often fails even in simple problems $[6,7]$. Usually, Multi-Objective Optimization Problems (MOOPs) use an optimization algorithm where a specific articulation between the different objectives is made through a single number, designated as fitness value, which measures the performance of a particular solution. Only optimization algorithms that can tackle various solutions at once can be used as Multi-Objective Optimization Algorithms (MOOA) [6, 7];

iv) generally, the need of obtaining reliable solutions requires the use of computationally demanding numerical modelling routines. Moreover, during optimization many modelling runs must be made. An alternative consists in using data mining techniques to develop simpler models, designated by meta or surrogate models. This type of approach relies on the concept of data-driven optimization, or in the use of AI techniques [8, 9], and has been previously applied to single screw extruders with innovative designs [10-13].

This work continues the task initiated in part 1 [5], discussing the application of optimization methods to solve practical problems in polymer processing, specifically involving injection molding, blow molding and thermoforming. The most important contributions to the topic are presented, and the corresponding objective function, process modelling approach, optimization algorithm and decision variables adopted are identified. 


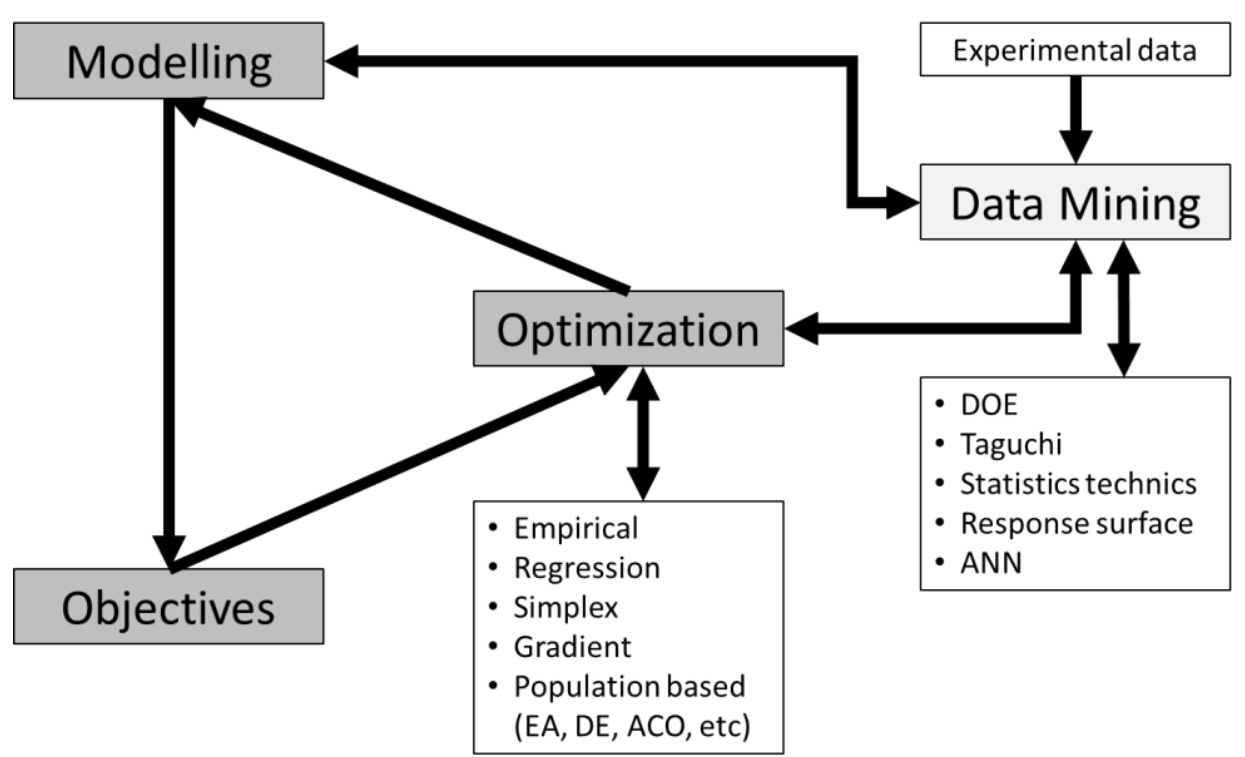

Figure 1. Optimization-based design framework.

\section{Optimization Algorithms in Polymer Processing}

\subsection{Methodology}

The methodology used here is identical to that adopted in Part I, dedicated to extrusion [5]. Thus, the investigation of the open literature on injection molding, blow molding and thermoforming of polymers is based on the following information:

1. Objective function, which can be pursued as a Single Objective (SO), Aggregated Product (AP), Aggregated Sum (AS) or Multi-Objective (MO);

2. Optimization algorithm, which can include Empirical, Regression, Direct, Gradient, Augmented Lagrangian (AL), Pattern Search (PS), Expert System (ES), Evolutionary Algorithm (EA), Differential Evolution (DE), Ant Colony Optimization (ACO), Stochastic Local Search (SLS), Two-Phase Local Search (TPLS);

3. Process modelling approach, which could be one-dimensional (1D), two-dimensional (2D) or three-dimensional (3D), Analytical (A), using Finite Differences (FD), Finite Volumes (FV) or Finite Elements (FE);

4. Decision variables, i.e., the process parameters to optimize;

5. Other characteristics, related with the process/modeling approach, optimization, etc.

\subsection{Injection Molding}

Injection molding involves two main stages, plasticizing the polymer followed by molding and cooling the part inside the mold, which can originate different types of optimization problems. The plasticizing step is comparable to plasticizing single screw extrusion (see part 1 [5]), the differences being related to the cyclic nature of injection molding, and with the axial screw displacement during plasticization and injection. In the case of the molding and cooling phases, the design of the cavity(ies), gate, runners system, and cooling channels, as well as defining the operating conditions can be tackled as optimization problems. Table 1 summarizes the many publications dealing with the optimization of these aspects. As expected, they embrace designing the screw of the plasticizing unit, balancing the runner system, locating the gate, outlining the cooling system, or setting the operating conditions.

Screw design will be discussed first, given its similarity with the design of screws for single screw extrusion, as discussed earlier [5]. This will be followed by an analysis of the literature in terms of the type of objective function, i.e., single objective, aggregation function, multi-objective, and optimization algorithm. 


\subsubsection{Plasticizing unit (screw design)}

Verbraak and Meijer [14] made a major contribution to screw design for injection molding by evaluating experimentally the performance of different screw geometries (conventional three zone screws with different compression ratios, screws containing pineapple, Maddock, or Egan mixing sections, static mixers as add-ons, and/or combinations of these solutions). They took individually into account the maximization of distributive and dispersive mixing, and of the plasticating capacity, and the minimization of melt temperature differences. In order to optimize injection molding screws considering together the operating conditions (screw speed) and screw geometry (channel depth and screw length), Huang [15] applied a grey relational analysis (a data analysis technique) based on the Taguchi method, using a commercial process modelling software, and evaluating the performance in terms of plasticating rate and melt temperature uniformity. Wang et al. [16] applied EA to design screws taking into account the length of the feed and compression zones, the depth of the metering zone and the flight thickness. An ANN was trained based on 3D numerical modelling results defined by the Taguchi method, and the performance was evaluated using the weighted sum of four objectives (maximize output, minimize melt temperature variation at the screw tip, minimize specific mechanical energy and minimize length for melting).

2.2.2 Single objective optimization

Concerning single objective optimization of injection molding, Seow and Lam [17] optimized the runners system layout in order to obtain a uniform pressure balance, by changing the thickness of the different flow paths using a trial-and-error procedure. Lee and Kim [18] optimized the injection velocity, cooling and packing times, packing pressure, melt temperature, and mold coolant temperature, with the aim of minimizing part warpage. The complex method was employed, which is a modification of the simplex method to take into account constraints.

Some authors optimized the process using regression analyses based on experimental results. Chang and Faison [19], Feng et al. [20] and Tang et al. [21] defined the operating conditions with a view to minimize shrinkage. The last two studies used a regression analysis and ANN based on experimental data. Ahmad et al. [22] applied the Taguchi method to analyze experimental data and find the operating conditions that minimize shrinkage. Mukras [23] proposed a framework for optimizing the operating conditions that minimize cycle time, while assuming volumetric shrinkage and warpage as constraints. The operating conditions were experimentally related with the objective and constraints by means of the Kriging model (also known as Gaussian process regression, which is an interpolation method based on a Gaussian process), and the selection of the optimal solution was made graphically. 
Table 1. Previous publications on the optimization of injection molding (SD- screw design, GL- gate location, OC- operating conditions, MD- mold design, CC- cooling channels, RS- runners system, CB- cavity balancing, PG- part geometry).

\begin{tabular}{|c|c|c|c|c|c|}
\hline $\begin{array}{l}\text { Objective } \\
\text { function }\end{array}$ & $\begin{array}{c}\text { Optimization } \\
\text { Algorithm }\end{array}$ & $\begin{array}{l}\text { Modelling } \\
\text { Approach }\end{array}$ & $\begin{array}{l}\text { Decision } \\
\text { variables }\end{array}$ & $\begin{array}{c}\text { Other } \\
\text { characteristics }\end{array}$ & Authors (year), reference \\
\hline $\mathrm{SO}$ & Empirical & Experimental & SD & $\begin{array}{c}\text { Various } \\
\text { geometries }\end{array}$ & Verbraak and Meijer (1989) [14] \\
\hline $\mathrm{SO}$ & Regression & $3 \mathrm{D}-\mathrm{N}$ & $\mathrm{SD}$ & & Huang (2016) [15] \\
\hline WS & EA & $3 \mathrm{D}-\mathrm{N}$ & $\mathrm{SD}$ & & Wang et al. (2020) [16] \\
\hline $\mathrm{SO}$ & Empirical & 3D-N & $\mathrm{CB}$ & & Seow and Lam (1997) [17] \\
\hline $\mathrm{SO}$ & Complex & $3 \mathrm{D}-\mathrm{N}$ & OC & & Lee and Kim (1995) [18] \\
\hline $\mathrm{SO}$ & Regression & Experimental & OC & DOE & Chang and Faison (2001) [19] \\
\hline $\mathrm{SO}$ & Regression & Experimental & OC & ANN & Feng et al. (2006) [20] \\
\hline $\mathrm{SO}$ & Regression & Experimental & OC & ANN & Tang et al. (2007) [21] \\
\hline $\mathrm{SO}$ & Regression & Experimental & OC & Taguchi & Ahmad et al. (2019) [22] \\
\hline $\mathrm{SO}$ & Regression & Experimental & $\mathrm{OC}$ & Kriging model & Mukras (2020) [23] \\
\hline $\mathrm{SO}$ & Regression & $3 \mathrm{D}-\mathrm{N}$ & $\mathrm{OC}$ & & Chen et al. (2010) [24] \\
\hline $\mathrm{SO}$ & Regression & 3D-N & $\mathrm{OC}$ & & Huang et al. (2015) [25] \\
\hline $\mathrm{SO}$ & Gradient & 3D-N & $\mathrm{GL}+\mathrm{OC}$ & & Smith et al. (1998) [26] \\
\hline $\mathrm{SO}$ & Gradient & $3 \mathrm{D}-\mathrm{N}$ & $\mathrm{CB}$ & & Lam and Seow (2000) [27] \\
\hline $\mathrm{SO}$ & Gradient & $3 \mathrm{D}-\mathrm{N}$ & GL & & Lam and Jin (2001) [28] \\
\hline $\mathrm{SO}$ & Gradient & $2 \mathrm{D}-\mathrm{N}$ & $\mathrm{CC}$ & SQP & Pirc et al. (2008) [29] \\
\hline $\mathrm{SO}$ & EA+Gradient & $2 \mathrm{D}-\mathrm{N}+3 \mathrm{D}-\mathrm{N}$ & GL & & Zhai et al. (2005) [30] \\
\hline $\mathrm{SO}$ & EA+Gradient & 2D-N & $\mathrm{CC}$ & & Qiao (2006) [31] \\
\hline $\mathrm{SO}$ & SA & 3D-N & GL & & Li et al. (2007) [32] \\
\hline $\mathrm{SO}$ & EA & $3 \mathrm{D}-\mathrm{N}$ & $\mathrm{OC}+\mathrm{GL}$ & & Ye and Wang (1999) [33] \\
\hline $\mathrm{SO}$ & EA & 3D-N & $\mathrm{OC}$ & ANN & Shi et al. (2003) [34] \\
\hline $\mathrm{SO}$ & EA & 3D-N & $\mathrm{OC}+\mathrm{CC}$ & & Lam et al. (2004) [35] \\
\hline $\mathrm{SO}$ & $\overline{E A}$ & 3D-N & $\mathrm{OC}$ & & Kurtaran et al. (2005) [36] \\
\hline $\mathrm{SO}$ & EA & $3 \mathrm{D}-\mathrm{N}$ & $\mathrm{CC}$ & & Ozcelik and Erzurumlu (2005) [37] \\
\hline $\mathrm{SO}$ & EA & $3 \mathrm{D}-\mathrm{N}$ & $\mathrm{OC}$ & ANN & Ozcelik and Erzurumlu (2006) [38] \\
\hline $\mathrm{SO}$ & EA & 3D-N & $\mathrm{OC}+\mathrm{RS}+\mathrm{PG}$ & & Wu et al. (2011) [3] \\
\hline $\mathrm{SO}$ & $\mathrm{ABC}$ & $3 \mathrm{D}-\mathrm{N}$ & $\mathrm{OC}$ & ANN & Iniesta et al. (2013) [40] \\
\hline $\mathrm{SO}$ & EA & $3 \mathrm{D}-\mathrm{N}$ & OC & ANN & Changyu et al. (2007) [41] \\
\hline $\operatorname{AS}(2)$ & Regression & Experimental & $\mathrm{OC}$ & Taguchi & Singh et al. (2018) [42] \\
\hline $\mathrm{AS}(8)$ & Regression & Experimental & $\mathrm{OC}$ & & Sreedharan et al. (2019) [43] \\
\hline $\mathrm{AS}(3)$ & Regression & Experimental & OC & Gray Rel. Anal. & Kumar et al. (2019) [44] \\
\hline $\mathrm{AS}(2)$ & Regression & $3 \mathrm{D}-\mathrm{N}$ & $\mathrm{OC}$ & RBF & Kitayama et al. $(2017,2018)[45,46]$ \\
\hline $\mathrm{AS}(3)$ & Regression & $3 \mathrm{D}-\mathrm{N}$ & $\mathrm{OC}$ & Fuzzy analysis & Moayyedian and Mamedov (2019) [47] \\
\hline $\mathrm{AS}(2)$ & Gradient & 3D-N & $\mathrm{CC}$ & & Tang et al. (1997) [48] \\
\hline $\mathrm{AS}(2)$ & Gradient & $3 \mathrm{D}-\mathrm{N}$ & $\mathrm{OC}$ & & Park and Kwon (1998) [49] \\
\hline $\operatorname{AS}(2)$ & Gradient & $3 \mathrm{D}-\mathrm{N}$ & $\mathrm{CC}$ & & Huang and Fadel (2001) [50] \\
\hline $\mathrm{AS}(4)$ & Gradient & $3 \mathrm{D}-\mathrm{N}$ & GL & & Shen et al. (2004) [51] \\
\hline $\operatorname{AS}(2)$ & Gradient & $3 \mathrm{D}-\mathrm{N}$ & $\mathrm{CC}$ & SQP & Mathey et al. (2004) [52] \\
\hline $\mathrm{AS}(2)$ & Gradient & 3D-N & $\mathrm{CC}$ & & Agazzi et al. (2010) [53] \\
\hline $\mathrm{AP}(3)$ & Gradient & 3D-N & $\mathrm{OC}$ & & Shie (2008) [54] \\
\hline $\mathrm{AS}(3)$ & Gradient+SA & 3D-N & GL and OC & & Pandelidis and Zou $(1990,1990)[55,56]$ \\
\hline $\mathrm{SO}+\mathrm{AS}(2)$ & $\begin{array}{c}\text { Gradient+ } \\
\text { EA+DE+SA }\end{array}$ & $3 \mathrm{D}-\mathrm{N}$ & OC & & Turng and Peić (2002) [57] \\
\hline
\end{tabular}


Table 1 (continued). Previous publications on the optimization of injection molding (SD- screw design, GL- gate location, OC- operating conditions, MD- mold design, CC- cooling channels, RS- runners system, CB- cavity balancing, PG- part geometry).

\begin{tabular}{cccccc}
\hline $\begin{array}{c}\text { Objective } \\
\text { function }\end{array}$ & $\begin{array}{c}\text { Optimization } \\
\text { Algorithm }\end{array}$ & Modelling & $\begin{array}{c}\text { Decision } \\
\text { variables }\end{array}$ & $\begin{array}{c}\text { Other } \\
\text { characteristics }\end{array}$ & Reference \\
\hline $\mathrm{AS}(2)$ & Gradient+EA & 3D-N & OC & & Lam et al. (2006) [58] \\
\hline $\mathrm{AS}(3)$ & EA & 3D-N & OC & Kim et al. (1996) [59] \\
\hline $\mathrm{AS}(2)$ & EA & Exp.+ANN & OC & Chen et al. (2007) [60] \\
\hline $\mathrm{AS}(3)$ & EA & 3D-N & OC & ANN & Meiabadi et al. (2013) [61] \\
\hline $\mathrm{AS}(4)$ & EA & 3D-N & OC+MD+PD & ANN & Mok et al. (2001) [62] \\
\hline $\mathrm{MO}(3)$ & EA & 3D-N & OC+RS & & Alam and Kamal (2003/04/05) [63,64,65] \\
\hline $\mathrm{MO}(3)$ & EA & 3D-N & OC & morphology & Gaspar-Cunha et al. (2005) [66] \\
\hline $\mathrm{MO}(5)$ & DEA & 3D-N & OC+GL & ANN & Castro et al. (2007) [67] \\
\hline $\mathrm{MO}(4)$ & EA & 3D-N & OC & & Fernandes et al. (2010) [68] \\
\hline $\mathrm{MO}(2)$ & EA & 3D-N & OC+CC & & Fernandes et al. (2012) [69] \\
\hline $\mathrm{MO}(3)$ & PSA & Experimental & OC & Taguchi+ANN & Xu et al. (2012) [70]
\end{tabular}

The above regression techniques have been used recently, but based on 3D numerical modelling results. Chen et al. [24], aiming to optimize nine operating conditions whilst assuming warpage as an objective and shrinkage as a constraint, applied the response surface method (data analysis) combined with nonlinear programming. Huang et al. [25] linked the Taguchi method with a grey relational analysis to find the best operating conditions (melt and mold temperatures, injection pressure and time, holding pressure) taking individually into account the minimization of warpage and of temperature distribution. The way the optimization was performed seems somewhat unclear, since the grey relation analysis is merely a data analysis method.

The gradient method has also been used together with 3D numerical modelling results. Smith et al. [26] optimized both the operating conditions and gate location that minimize the filling time. Lam and Seow [27] applied the same strategy to perform cavity balancing, while Lam and Jin [28] determined the operating conditions that minimized the standard deviation of the flow path or filling time. Pirc et al. [29] designed the mold cooling channels (lengths and diameters) in order to minimize the maximum polymer temperature using sequential quadratic programming(SQP).

Simultaneously, some authors applied more elaborated algorithms, e.g., Simulated Annealing (SA), Evolutionary Algorithms (EA) and Artificial Bee Colony (ABC), to optimize injection molding, although based on a single objective function. Zhai et al. [30] applied EA with 2D modelling and the gradient method with 3D modelling to find the gate location that minimized the injection pressure. These algorithms were also used by Qiao [31] to optimize the location of the cooling channels that minimize the standard deviation of the cavity surface temperature. Li et al. [32] used simulated annealing to optimize the gate location, aiming to reduce warpage.

Single objective optimization using EAs targeted mainly the definition of the operating conditions. Ye and Wang [33] optimized the gate location and the operating conditions with the aim of maximizing the pressure at the end of the filling step. Shi et al. [34] defined the operating conditions that minimize the maximum shear stress in the mold cavities. Lam et al. [35] determined the operating conditions and geometry of the cooling channels that minimize the standard deviation of the cavity surface temperature. Kurtaran et al. [36] optimized the operating conditions in order to minimize warpage, while Ozcelik and Erzurumlu [37, 38] and Wu et al. [39] optimized both the operating conditions and several dimensional parameters of the part or mold, also to minimize warpage. With identical aim, Iniesta et al. [40] used the hybridization of ANN and artificial bee colony (ABC) algorithms. The results were obtained using a 3D numerical modelling software and the ANN was applied to map the objectives as a function of the decision variables. Finally, Changyu et al. [41] defined the operating conditions that minimize volumetric shrinkage. 


\subsubsection{Aggregation function optimization}

Several studies dedicated to optimize injection molding assumed simultaneously various objectives via an aggregation function, and adopted data analysis techniques (for example, the Taguchi method) to define the experimental/computational results to be obtained, and a specific technique to fit the data to a regression model. Singh et al. [42] developed an approach based on the hybridization of Taguchi and desirability function techniques to optimize the operating conditions that minimize cycle time and warpage. The experimental data was fitted to a multiple response surface (data analysis). Sreedharan $e t$ al. [43] also applied data analysis to the experimental results based on grey relational and principal component analyses, to generate a response surface and optimize the operating conditions in order to nine objectives that were aggregated in a single function using a weighted sum. Kumar et al. [44] conducted experiments according to the Taguchi L27 Orthogonal Array, and analyzed and optimized the response data using the Grey Relational Analysis (an evaluation technique able to solve complex problems for which only incomplete information exists) and a multivariate analysis. The operating conditions that minimize shrinkage, warpage, and surface roughness were identified. Kitayama et al. [45] proposed a strategy for taking into consideration various objectives based on the usage of a radial basis function (i.e., a technique able to fit data to a mathematical function), the aim being to set the operating conditions that minimize cycle time and warpage. For that purpose, the authors considered the weight sum of the objectives and generated successive Pareto fronts after analyzing the previous ones. In reality, this is a data analysis method, since a fit to data is applied. Later, the same optimization methodology was adopted to define the values of the same operating parameters that maximize the minimum weld line temperature and minimize the clamping force [46]. Finally, Moayyedian et al. [47] applied the Taguchi method and a fuzzy analytic hierarchy process to rank the performance of the solutions quantified by a moldability index, which corresponds to a type of weighted sum of the objectives considered. The aim was to determine the operating conditions (melt temperature, gate design, filling and cooling times) that minimize shrinkage, warpage and short shots).

Gradient optimization techniques were also used in numerous studies with the aim of optimizing operating conditions, gate location and layout of the mold cooling channels. Tang et al. [48] defined the geometry and location of the cooling channels that minimize both the maximum temperature and the temperature gradient, whereas Park and Kwon [49] determined the operating conditions that minimize the average temperature of the molding and the cooling time. Huang and Fadel [50] defined the geometry of the cooling channels that minimize the maximum temperature difference in the part and the cycle time. Shen et al. [51] optimized the gate location with the aim of minimizing the pressure, the filling time difference between different paths, the temperature difference in the part and the percentage of overpacking. Mathey et al. [52] optimized the location and geometry of the cooling channels that maximize the cooling efficiency and rate, using a specific gradient method (sequential quadratic programing). Similarly, Agazzi et al. [53] designed the cooling channels, but in order to minimize temperature and temperature gradient. Shie [54] defined the operating conditions that maximize tensile strength, minimize wear and minimize warpage of the part, considering the product of the objectives.

Several studies adopted Simulated Annealing, Evolutionary Algorithms or a combination of different techniques. For example, Pandelidis and Zou $[55,56)$ combined gradient and SA methods to define the gate location and the operating conditions that minimized temperature differences in the part, warpage and material degradation. Turng and Peic [57] proposed an integrated tool based on the link between a 3D numerical modelling commercial package and an optimization framework through a single or aggregated objective function, taking into account the relevant constraints, and the possibility of choosing between different optimization algorithms (e.g., gradient, EA, DE and SA). The authors applied this tool to two case studies involving the optimization of the operating conditions, one considering a single objective (minimization of shrinkage in length), the 
other the weighted sum of two objectives (minimization of cycle time and volumetric shrinkage). Lam et al. [58] unveiled the operating conditions that minimized the maximum shear stress and the maximum cooling time.

Single objective EAs were used to optimize the part, mold design and operating conditions. Kim et al. [59] aimed at minimizing simultaneously the temperature difference in the part, overpacking and frictional overheating. Chen et al. [60] attempted to minimize both part length and weight, whilst Meiabadi et al. [61] focused on minimizing the maximum pressure, part weight and cycle time. In most cases, the results were obtained using data from a 3D numerical modelling software, except in [60] where experimental results were mapped using an ANN. Finally, Mok et al. [62] optimized the part, mold design and operating conditions, with a view to minimize maximum wall shear stress, maximum representative shear rate, maximum temperature difference in the part and cycle time.

\subsubsection{Multi-objective optimization}

Alam and Kamal $[63,64,65]$ optimized runners diameters and lengths, as well as the operating conditions that minimized the runner-system volume, cycle time and local part shrinkage differences. Gaspar-Cunha et al. [66] linked a MOEA to a commercial 3D numerical modelling code and determined the operating conditions that induced a specific morphology that was characterized in terms of thermomechanical indices (skin thickness, degree of crystallinity and/or level of molecular orientation). Castro et al. [67] tackled the optimization of the operating conditions and gate location using Data Envelopment Analysis (a multi-objective algorithm) and employing an ANN (which was trained using numerical results) to map the objective as a function of the decision variables. Fernandes et al. [68] applied a MOEA to optimize the operating conditions that minimized temperature differences in the molding at the end of the filling stage, the maximum cavity pressure, the pressure work (i.e., the integral of pressure over time), shrinkage and cycle time. Figure 2 exemplifies the results obtained when minimizing simultaneously volumetric shrinkage (VS) and pressure work (PW). Figure 2-A shows the evolution of the Pareto curves along the various generations, displaying a clear improvement. Figure 2-B depicts the decision variables and objectives values for two solutions ( 1 and 3 ). Not only the tradeoff between the two objectives is clear, but it seems that, as expected, holding pressure $(\mathrm{Ph})$ is the most influencing variable. Figure 2-C presents a good match between these solutions and the modelling results for the evolution of pressure with time, as well as that solution 2 is more equilibrated concerning the pressure work. Later, using the same MOEA, the locations and diameters of the cooling channels were also optimized, together with the operating conditions, in order to minimize warpage and cycle time [69]. Xu et al. [70] identified the operating conditions that minimized part weight, volume shrinkage and flash, using a multi-objective particle swarm optimization algorithm, and the results given by a ANN trained with experimental data defined by a Taguchi method. 
(A)

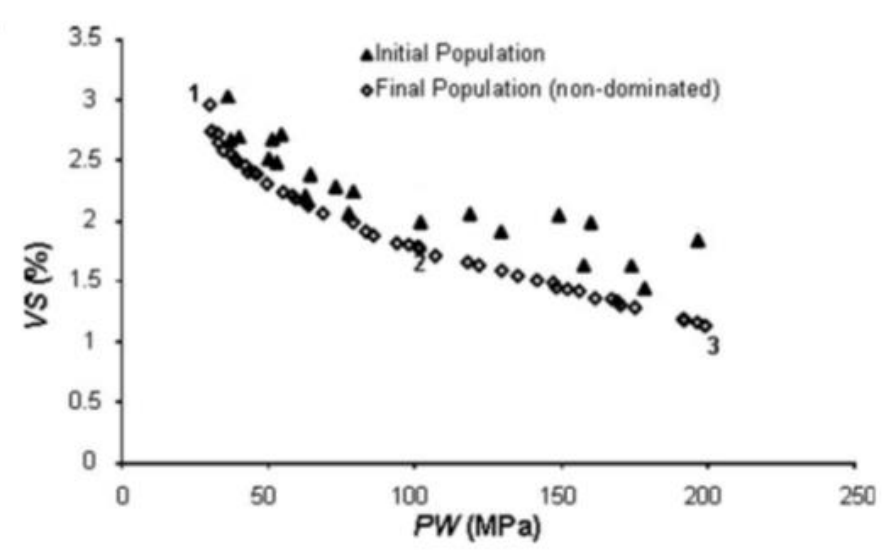

(C)
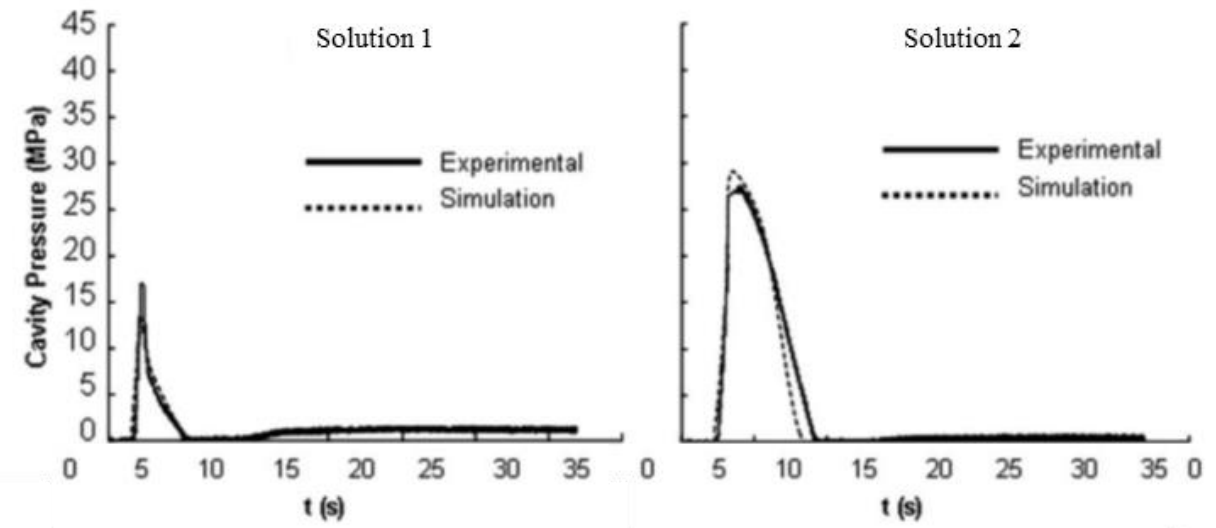
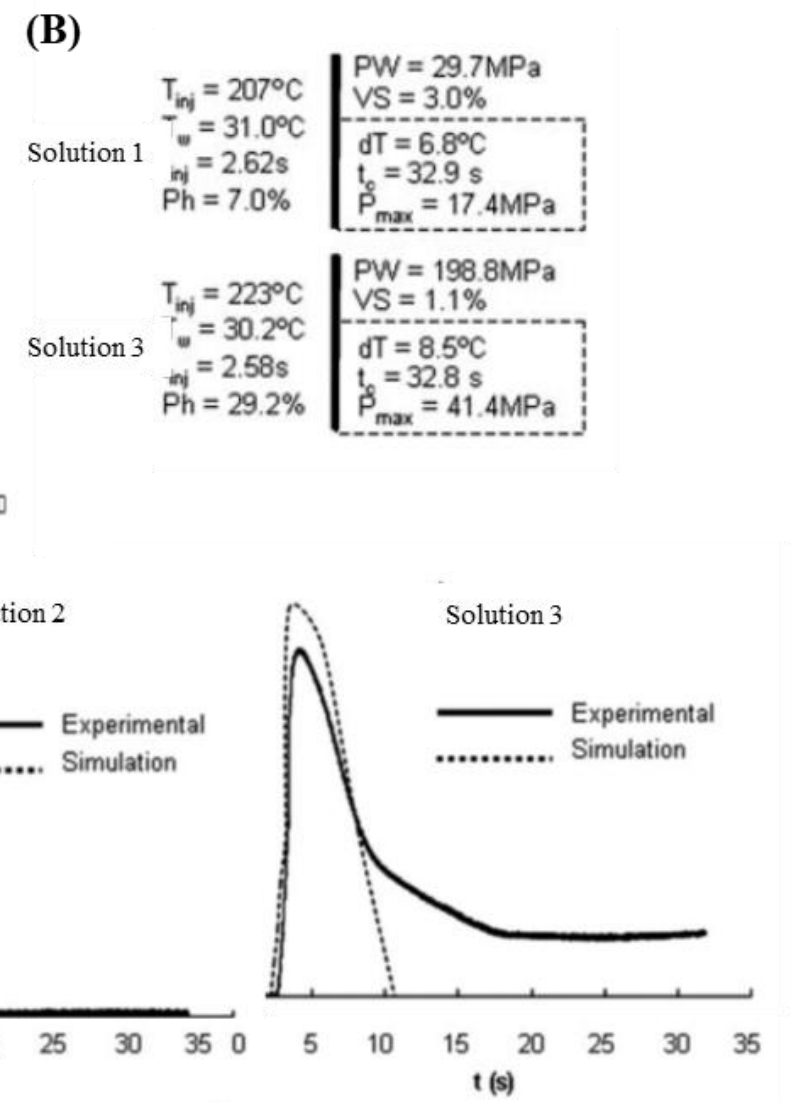

Figure 2. Multi-objective optimization of the operating conditions for injection molding: (A) Pareto curves; (B) Decision variables and objective values for the optimized solutions; (C) Experimental assessment (adapted from [68]).

\subsection{Blow-Molding}

Table 2 identifies the reported attempts to optimize blow molding, providing the same type of data as the previous table. The technology being mostly used for the packaging sector, the focus of optimization is often to reduce the weight of the part in order to reduce the amount of required material, while retaining its performance. The discussion is organized according to each specific processing technology, i.e., extrusion blow molding and injection blow molding.

\subsubsection{Extrusion blow molding}

Tahboub and Rawabdeh [71] employed a design of experiments to optimize the operating conditions (screw speed, melt temperature, cooling time, blowing pressure, blowing time and mold temperature) that minimized the variability with time of the volume of the container. Agrawal et al. [72] applied a statistical data analysis based on the Taguchi method and a Grey relational analysis to establish the operating conditions that maximized the compressive strength and volume accuracy of the part. Likewise, Dohare et al. [73] found the operating conditions that maximized haze and clarity, hardness and compressive strength, based on experimental data. DiRaddo and Garcia-Rejon [74] proposed a simple iterative procedure (Newton-Raphson technique) to define the parison thickness profile capable of minimizing the overall thickness variations of the final part, the solutions proposed being obtained with a 3D numerical modelling software. Thibault $e t$ al. [75] and Gauvin et al. [76] suggested a multi-disciplinary design optimization (MDO) software environment for optimizing the process. The authors considered two steps: first, the mechanical performance of the blown part was optimized in order to delineate the optimal part thickness distribution; then, the die gap variation minimizing the part thickness variance was established. A single objective was considered - minimizing part weight, together with a constraint regarding a minimum mechanical requirement. Given the significant computation time required by the numerical process modelling, a ANN 
based on the Tagugchi method was trained to define the computational samples and establish relations between the design variables and the objectives; the gradient technique was used in the first step, an EA was applied in the second step [77, 78, 79]. Later, the same team proposed an EA optimization technique together with an ANN and the Taguchi method, to optimize the die gap variation that minimized part weight while satisfying a few constraints [80]. Huang and Huang [81] determined the parison thickness distribution that produced a part with a predefined thickness profile. For that purpose, an EA together with an ANN were used to evaluate the solutions. Figure 3 illustrates the optimization of the parison thickness profile undertook. Two parisons with different thickness profiles were used (figure 3-A), one with uniform thickness, the other with an optimized profile (minimizing the differences between the profile obtained and the one targeted (Figure 3B)). The figure compares the thickness profiles of the part obtained from parisons with uniform thickness and with the optimized profile.

Table 2. Previous publications on the optimization of blow molding. Decision variables: OC- operating conditions; PaTP- parison thickness profile; PTP- part thickness profile; PfTP- preform thickness profile; PfTemP- preform temperature profile; DGOdie gap opening.

\begin{tabular}{|c|c|c|c|c|c|}
\hline $\begin{array}{l}\text { Objective } \\
\text { function }\end{array}$ & $\begin{array}{l}\text { Optimization } \\
\text { Algorithm }\end{array}$ & $\begin{array}{l}\text { Modelling } \\
\text { Approach }\end{array}$ & $\begin{array}{l}\text { Decision } \\
\text { variables }\end{array}$ & $\begin{array}{l}\text { Processing } \\
\text { Technology }\end{array}$ & Reference \\
\hline $\mathrm{SO}$ & Regression & Experimental & $\mathrm{OC}$ & Extrusion & Tahboub and Rawabdeh (2004) [71] \\
\hline $\mathrm{SO}$ & Regression & Experimental & $\mathrm{OC}$ & Extrusion & Agrawal et al. (2012) [72] \\
\hline $\mathrm{SO}$ & Regression & Experimental & $\mathrm{OC}$ & Extrusion & Dohare et al. (2018) [73] \\
\hline $\mathrm{SO}$ & Gradient & $3 \mathrm{D}$ & PaTP & Extrusion & Diraddo and Garcia-Rejon (1993) [74] \\
\hline $\mathrm{SO}$ & Gradient & $3 \mathrm{D}$ & PTP & Extrusion & Thibault et al. (2001) [75] \\
\hline So & Gradient & $3 \mathrm{D}$ & $\mathrm{PTP}+\mathrm{DGO}$ & Extrusion & Gauvin et al. (2003) [76] \\
\hline $\mathrm{SO}$ & Gradient+EA & $3 \mathrm{D}$ & PTP+DGO & Extrusion & Yu et al. $(2002,2004)[77,78]$ \\
\hline $\mathrm{SO}$ & Gradient+EA & $3 \mathrm{D}$ & $\mathrm{PTP}+\mathrm{DGO}$ & Extrusion & Hsu et al. (2004) [79] \\
\hline $\mathrm{SO}$ & Gradient & $3 \mathrm{D}$ & DGO & Extrusion & Yu and Juang (2010) [80] \\
\hline $\mathrm{SO}$ & EA & $3 \mathrm{D}$ & PTP & Extrusion & Huang and Huang (2007) [81] \\
\hline $\mathrm{SO}$ & Empirical & $3 \mathrm{D}$ & PfTP & Injection & Hopmann et al. (2015) [82] \\
\hline $\mathrm{SO}$ & Simplex & $3 \mathrm{D}$ & PfTP & Injection & Bordival et al. (2009) [83] \\
\hline $\mathrm{SO}$ & Simplex & $3 \mathrm{D}$ & PfTP & Injection & Biglione (2015) [84] \\
\hline $\mathrm{SO}$ & Simplex & $3 \mathrm{D}$ & PfTP & Injection & Biglione et al. (2016) [85] \\
\hline $\mathrm{SO}$ & Regression & Experimental & $\mathrm{OC}$ & Injection & Demirel (2017) [86] \\
\hline $\mathrm{SO}$ & Gradient & $3 \mathrm{D}$ & PfTP & Injection & Lee and Soh (1996) [87] \\
\hline $\mathrm{SO}$ & Gradient & $3 \mathrm{D}$ & PfTP+OC & Injection & Thibault et al. (2007) [88] \\
\hline $\mathrm{MO}(3)$ & EA & $3 \mathrm{D}$ & PTP & Injection & Denysiuk et al. $(2017,2019)[89,90]$ \\
\hline $\mathrm{MO}(3)$ & EA & $3 \mathrm{D}$ & PTP & Injection & Pinto et al. (2019) [91] \\
\hline $\mathrm{MO}(3)$ & EA & $3 \mathrm{D}$ & PfTP & Injection & Pinto et al. (2021) [92] \\
\hline
\end{tabular}



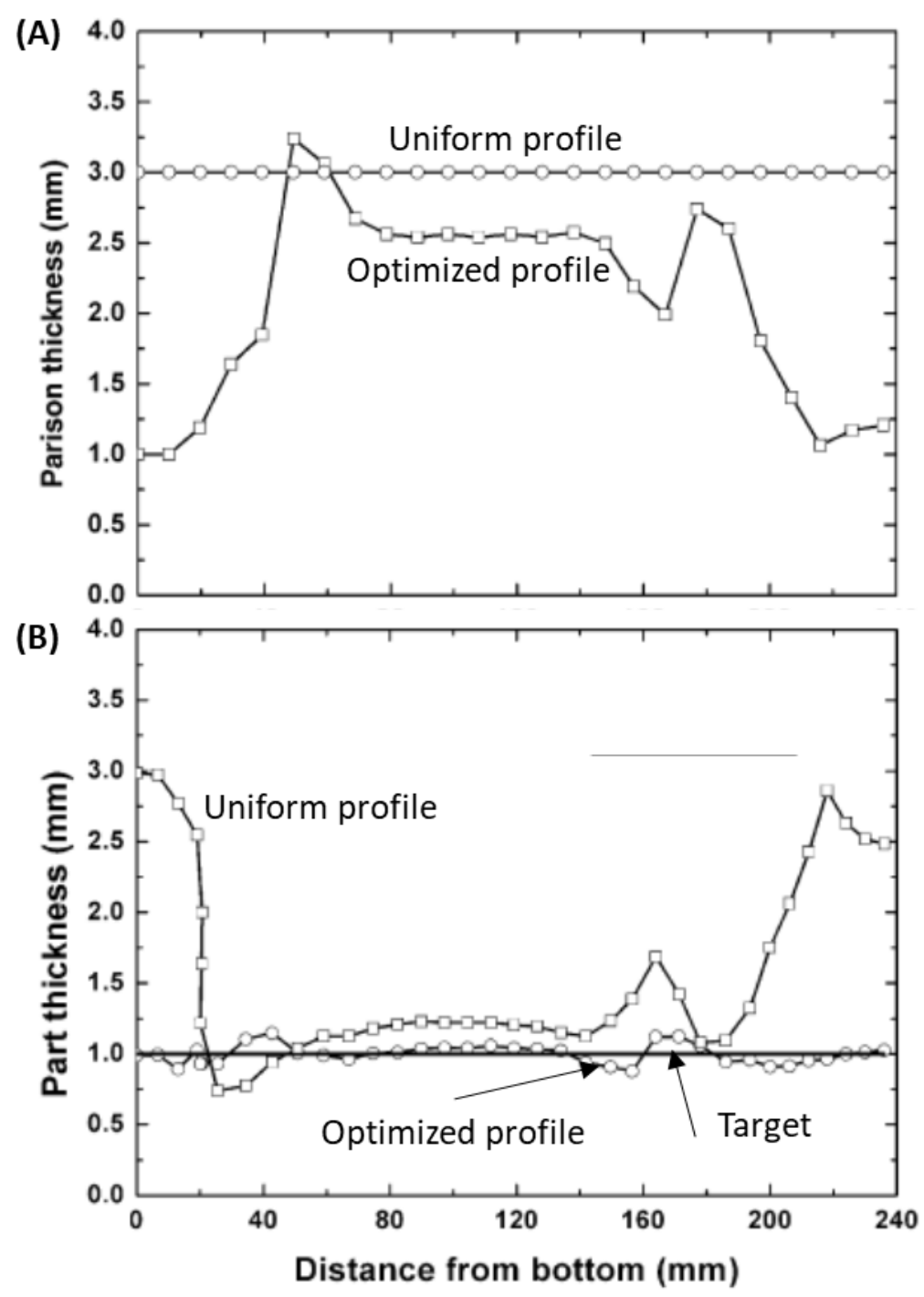

Figure 3. Optimization of the parison thickness profile for extrusion blow-molding: (A) initial uniform and optimized parison profile; (B) Part thickness profile after blowing obtained from uniform and optimized parison profiles, together with the target profile (adapted from [81]).

\subsubsection{Injection blow molding}

Hopmann et al. [82] determined the thickness distribution of the injected preform that created a blown bottle with a specific wall thickness distribution. The modelling results were obtained using a response surface methodology based on 3D numerical computations, while the optimization was supported by an empirical approach. Bordival et al. [83] applied a Simplex method (the Nelder-Mead optimization algorithm) to define the adequate axial temperature distribution of the preform making a bottle with uniform thickness, using results obtained with a 3D modelling software. The preform thickness profile was also optimized by Biglione et al. [84, 85], who attempted to minimize the normalized square root of the difference between the predefined bottle thickness profile and the thickness profile calculated for the solutions by a 3D numerical software. For that purpose, the simplex method and a simple predictor/corrector iterative method were used successively. Demirel [86] used a design of experiments and a response surface method to define, based on experimental data, the operating conditions related with the blowing stage (mold surface temperature and residence time of the bottle in the mold) that optimized the performance of the part (in terms of mechanical and thermal properties).

Lee and Soh [87] determined the thickness profile of a preform that created a part with a pre-defined thickness contour, while satisfying two constraints (a minimum wall 
thickness and the absence of undercuts in the inner surface of the preform). The Brent algorithm (a single objective optimization method based on gradient) was applied, and a 3D numerical modelling software supplied the results. Thibault et al. [88] optimized the preform thickness and the operating conditions for injection stretch blow molding, using a gradient-based optimization strategy based on two steps. First, the thickness distribution that minimized the preform weight while satisfying a few constraints (top load, pressurization and vacuum load) was defined, then the operating conditions were optimized.

Given the multi-objective nature of these problems, MOEA were combined with ANN $[89,90,91]$. A MOEA was applied to find the best solutions, i.e., to obtain the best trade-off between material usage and mechanical properties, whereas ANN was used to represent thickness distributions. The process was modeled using the ANSYS commercial numerical code. The aim was to determine the best thickness profile for the bottle that assured the desired mechanical properties with minimal material usage. Recently, Pinto et al. [92] found the best thickness profile for the preform that would produce the bottle that was previously optimized. In Figure 4, Solutions S1 and S2 for two different case studies were selected from the corresponding Pareto fronts (figure 4-A) and the thickness profile of these solutions was compared with the target (desired) profile (figure 4-B).
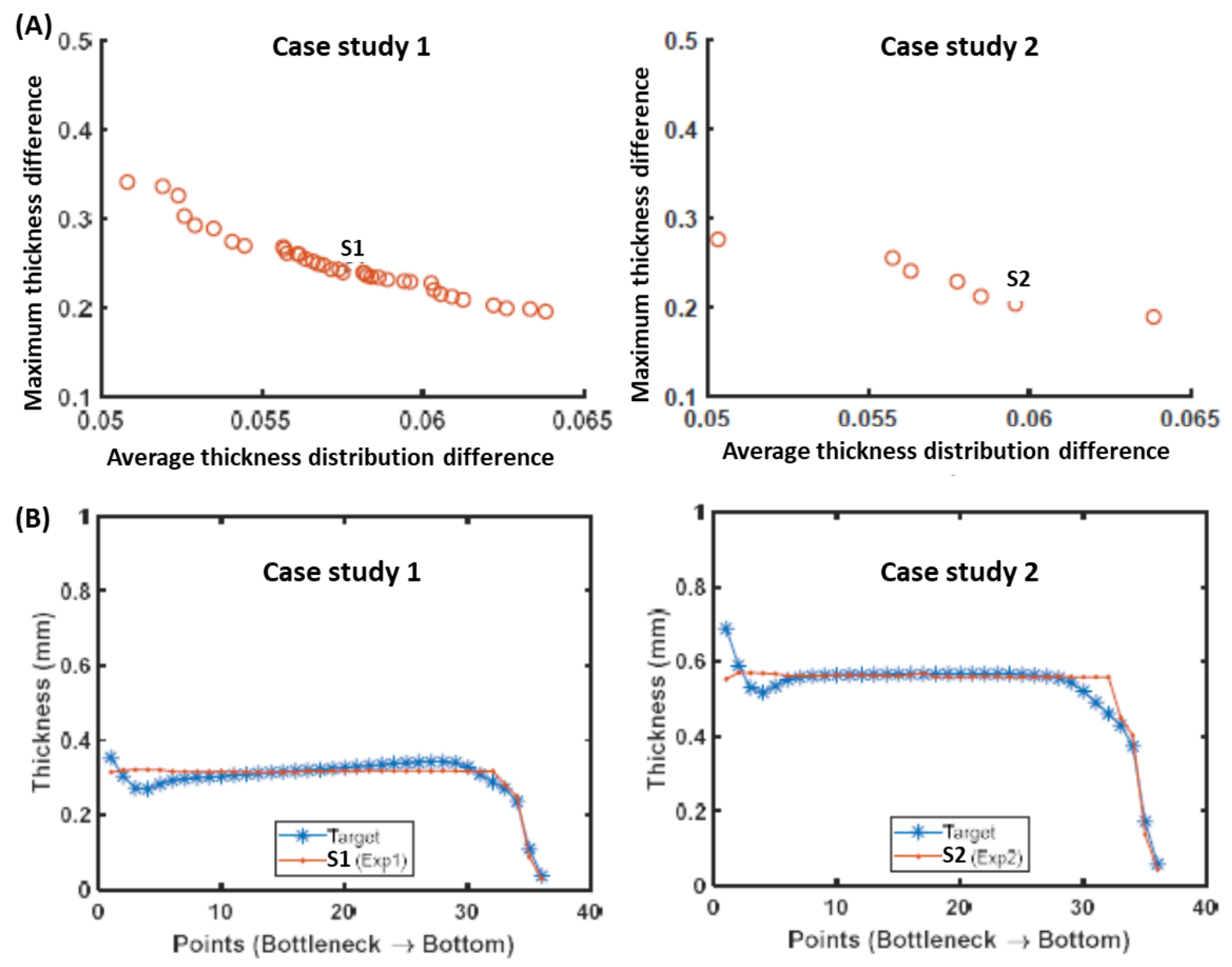

Figure 4. Multi-objective optimization of the preform to obtain the target bottle previously optimized for two case studies: (A) Pareto front, average thickness distributions difference between the obtained and the target bottles versus maximum thickness difference between obtained and target bottles; (B) comparison between the target bottle profile and the bottle profile obtained for optimized solutions S1 and S2 (adapted from [92]).

\subsection{Thermoforming}

The term thermoforming covers several technologies that use pressure (either positive or vacuum), eventually assisted by mechanical means, to force a heated sheet against the inner contours of a mold. Typically, these processes involve a sequence of interdependent stages (heating a sheet, forcing its deformation against a mold and cooling the 
part), which are dominated by the thermal (heat conduction, emissivity) and mechanical (extensional deformation and deformation rate capacity) properties of the polymer.

The deformation mechanisms developing in thermoforming techniques may create a significant thickness gradient in the final part, which may affect negatively its performance under service. Therefore, optimization challenges often involve finding the best operating conditions (generally, sheet temperature distribution at the end of the heating stage) and/or mold cavity geometry enabling to obtain, as much as possible, a part with a uniform/specific thickness distribution. Table 3 identifies previous efforts to attain these goals.

Table 3. Previous publications on the optimization of thermoforming (decision variables: OC- operating conditions; TempDtemperature distribution; SThD- sheet thickness distribution).

\begin{tabular}{|c|c|c|c|c|c|}
\hline $\begin{array}{l}\text { Objective } \\
\text { function }\end{array}$ & $\begin{array}{l}\text { Optimization } \\
\text { Algorithm }\end{array}$ & $\begin{array}{l}\text { Modelling } \\
\text { Approach }\end{array}$ & $\begin{array}{l}\text { Decision } \\
\text { variables }\end{array}$ & $\begin{array}{c}\text { Other } \\
\text { characteristics }\end{array}$ & Reference \\
\hline $\mathrm{SO}$ & Empirical & $1 \mathrm{D}-\mathrm{N}$ & TempD & & Duarte and Covas $(1997,2002)[93,94]$ \\
\hline $\mathrm{SO}$ & Gradient & $3 \mathrm{D}-\mathrm{N}$ & TempD & & Wang and Nied (1998) [95] \\
\hline $\mathrm{SO}$ & Gradient & $1 \mathrm{D}-\mathrm{A}$ & TempD & & Bordival et al. (2005) [96] \\
\hline $\mathrm{SO}$ & Gradient & $3 \mathrm{D}-\mathrm{N}$ & TempD & & Chy and Boulet (2010) [97] \\
\hline $\mathrm{SO}$ & Gradient & $3 \mathrm{D}-\mathrm{N}$ & TempD & & Chy et al. (2011) [98] \\
\hline $\mathrm{SO}$ & Regression & $3 \mathrm{D}-\mathrm{N}$ & TempD & & Li et al. (2008) [99] \\
\hline $\mathrm{SO}$ & Regression & $3 \mathrm{D}-\mathrm{N}$ & TempD & & Li et al. (2010) [100] \\
\hline $\mathrm{SO}$ & $\mathrm{SA}+\mathrm{EA}$ & $3 \mathrm{D}-\mathrm{N}$ & TempD & & Erchiqui et al. (2011 [101]) \\
\hline $\mathrm{SO}$ & $\mathrm{SA}+\mathrm{EA}$ & $3 \mathrm{D}-\mathrm{N}$ & TempD & & Bachir-Cherif et al. (2015) [102] \\
\hline $\mathrm{SO}$ & $\mathrm{SA}+\mathrm{EA}$ & $3 \mathrm{D}-\mathrm{N}$ & TempD & & Erchiqui (2018) [103] \\
\hline $\mathrm{SO}$ & Gradient & $3 \mathrm{D}-\mathrm{N}$ & TempD & & Bachir-Cherif et al. (2018) [104] \\
\hline $\mathrm{SO}$ & $\mathrm{SA}+\mathrm{EA}$ & $3 \mathrm{D}-\mathrm{N}$ & TempD & & Bachir-Cherif (2019) [105] \\
\hline $\mathrm{SO}$ & IANN & Experimental & $\mathrm{OC}$ & Plug assisted & Yang and Hung (2004) [106] \\
\hline $\mathrm{SO}$ & IANN & Experimental & $\mathrm{OC}$ & Plug assisted & Chang et al. (2005) [107] \\
\hline $\mathrm{SO}$ & Regression & Experimental & $\mathrm{OC}$ & Vacuum & Leite et al. $(2018,2018)[108,109]$ \\
\hline $\mathrm{SO}$ & Regression & Experimental & OC & Vacuum, pre-blow & Sasimowski (2018) [110] \\
\hline $\mathrm{MO}(2)$ & EA & $3 \mathrm{D}-\mathrm{N}$ & SThD & Plug assisted & Gaspar-Cunha et al. (2021) [111] \\
\hline
\end{tabular}

The inverse heating problem consists in defining the temperatures of the heaters panel that will produce a uniform sheet temperature, or a specific temperature distribution, after a given heating time. This was solved by Duarte and Covas $[93,94]$. Obviously, the temperature of the sheet at the beginning of the forming stage will influence the resulting thickness differences in the part, as it determines the local mechanical response of the polymer. Wang and Nied [95] used a gradient optimization method to define the optimal temperature distribution in the sheet. They started by defining the desired thickness profile, and then used 3D numerical modelling to solve iteratively the system for the temperature field needed to obtain the desired result. The iterations started with a uniform temperature distribution. Bordival et al. [96] applied a gradient method (sequential quadratic programming) coupled to a simple analytical model to define the optimized set of operative parameters that allowed to obtain the optimal temperature of the sheet, using a cost function representing the heat flux uniformity. In a subsequent step, these results were used to compute the contribution of the radiation heating resulting from the interaction between the heaters and the thermoplastic sheet. At the end, the three dimensional transient heat transfer equation was solved using a volume control method. Chy et al. [97, 98] used a conjugated gradient optimization method to solve the same problem. This automatic optimization methodology was applied using a complicated scheme with a high number of inputs and outputs for accurate control of sheet temperatures. The authors concluded that both heat transfer by radiation and conduction have an important role, 
making this a very complex task. Li et al. [99, 100] optimized the process employing a response surface coupled to the D-optimal method. First, a 3D numerical modelling software yielded uniform sheet temperature by achieving a steady-state optimum distribution of heater power. Then, the optimization methodology was used to determine the time-dependent optimal heater input by minimizing the temperature difference across the thickness. Erchiqui et al. [101, 102] and Bachir-Cherif et al. [103, 104] applied two different meta-heuristic algorithms (simulated annealing and evolutionary algorithms), and adopted a 3D volumetric enthalpy-based computational method to determine the optimal sheet temperature distribution. The same authors also applied a gradient based technique to the same problem [105].

Several studies focused on the optimization of the sheet deformation stage, with the objective of obtaining parts with as much as possible uniform thickness. Yang and Hung [106] proposed an Inverse Artificial Neural Network (IANN) to define the operating conditions (sheet temperature, vacuum pressure, plug speed and vertical displacement inside the mold) that maximized the part thickness uniformity. The inputs of the ANN (which was trained with experimental data) were the thickness distribution at different part locations, while the outputs were the corresponding operating conditions. A similar strategy was adopted to optimize the operating conditions of polypropylene foam thermoforming [107]. Leite et al [108, 109] applied a response surface methodology to solve the same type of problem. A ANN based on experimental data (consisting of an aggregation of different ways of calculating the difference between the thickness of the parts obtained and the desired thickness profile) related the decision variables with the objective. Sasimowski [110] applied the same strategy to identify the operating conditions (heating time, heater temperature, pre-blow time, vacuum time and cooling time) that created a more uniform thickness distribution in the parts. These contributions used ANN to obtain output values from a set of input experimental data. This procedure is analogous to using a regression model, hence their applicability is restricted to the specific cases studied.

The above methods optimized separately the individual process steps. However, since the input of one stage depends on the outcome of the preceding one, only assuming their interdependency enables a truly efficient process optimization. Gaspar-Cunha et al. [111] used a multi-objective evolutionary algorithm to define the initial sheet thickness profile that will induce a uniform thickness distribution in the part, while minimizing the quantity of material used. Three optimization conditions were equated to produce the same part: i) sheet with uniform thickness; ii) sheet with thickness varying transversally to the extrusion direction with a spline shape; and iii) sheet with concentric thickness variation with spline shape. The solutions were evaluated using a 3D numerical modelling software. Figure 5 presents three optimized solutions for each case. 


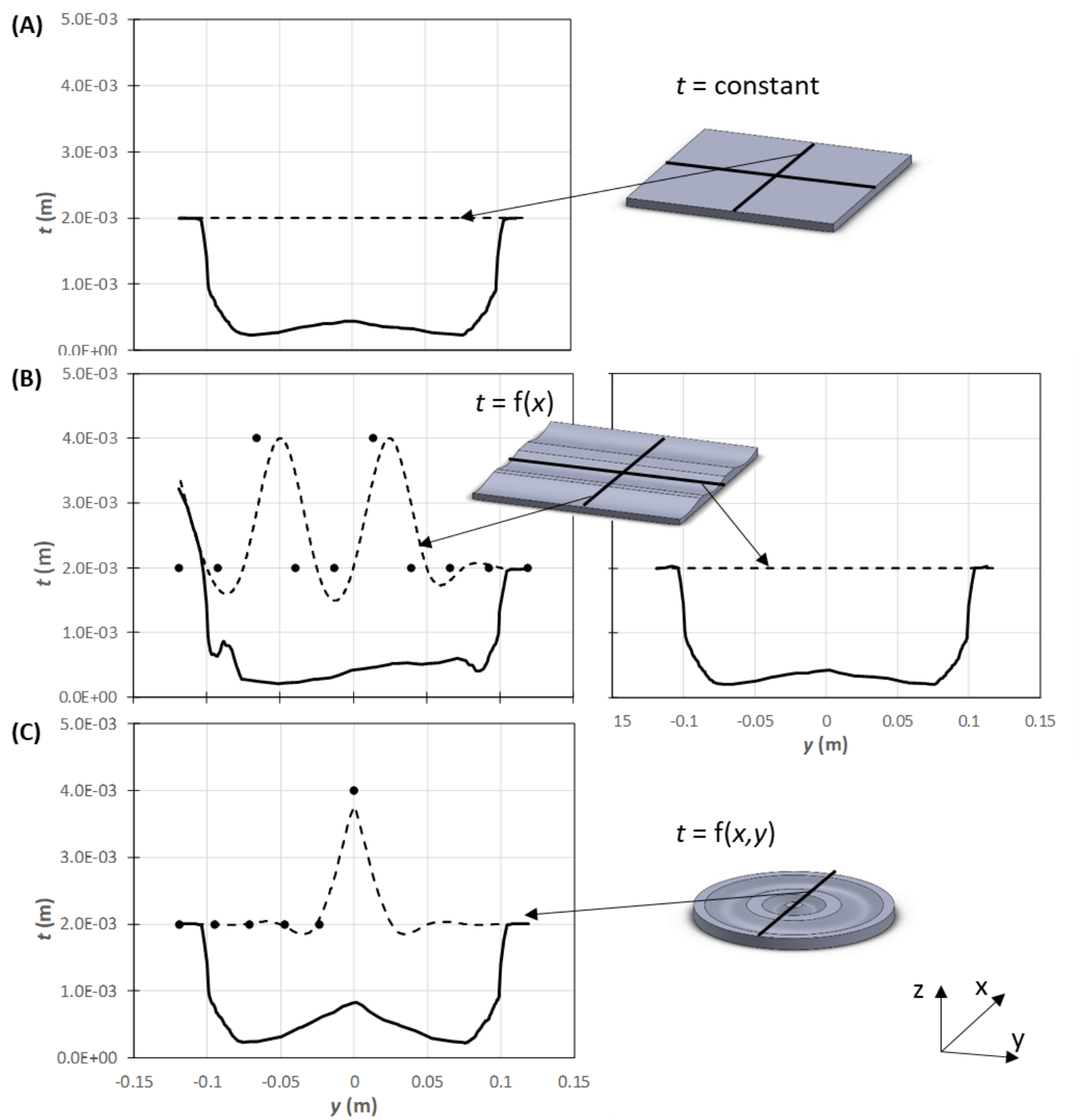

Figure 5. Multi-objective optimization of the initial sheet thickness profile that will induce a uniform thickness distribution in the part and minimize the quantity of material used: (A) sheet with uniform thickness; (B) sheet with thickness varying transversally to the extrusion direction with a spline shape; and (C) sheet with concentric thickness variation with spline shape. The dashed lines represent the sheet profile generated from the points in (B) and $(\mathrm{C})$, the continuous line represents the thickness profile of the part (adapted from [111].

\section{Conclusions}

This review discussed the application of optimization methodologies to the most important thermoplastics processing technologies. The existence of a strong interdependence between objective function, optimization algorithm and data collecting (i.e., experimental or computational data) is evident.

When approaching real processing situations as optimization problems, at least two objectives must be considered in order to reach valuable conclusions, as different aspects are to be analyzed simultaneously, i.e., processing problems are multi-objective.

Selecting an optimization algorithm depends on the problem features, and whether the goal is to optimize one or several objectives. Even if a few objectives exist, any type of optimization algorithm can be applied by simply aggregating them into a single objective. 
However, aspects such as data scarcity, the possibility of generating data during the optimization, and the time required to obtain such data, should also be taken into consideration.

The results produced using statistical, ANN, response surface and other regression methods are of limited value, as only a few parameters are used, either in the domain of the decision variables or in that of the objectives. Statistical approaches require a high amount of data, thus a significant number of simulations is required in order to define a good response surface, but without guaranteeing that the optimization will not be stuck in a local optimum instead of reaching the global one. Moreover, the optimization is intrinsically connected to the specific situation under consideration. If either the polymer properties, the operating conditions and/or the equipment geometry change, a complete new analysis must be carried out. Thus, regression methods are not very distinct from trial-and-error procedures where the optimization progresses with the help of the user.

Artificial Intelligence (AI) techniques, such as EAS, ANN, DE and data mining seem efficient approaches to address the optimization of complex polymer processing problems, as they are able to provide continuous or discrete solutions, use available data through a learning process, and deal efficiently with multiple objectives.

An optimization run is only successfully concluded when the preferences of a decision maker were introduced in a given process step, and the best solution has been chosen. The decision maker can be a human or a machine (which can link optimization with Artificial Intelligence). In this way, AI technologies used in other fields can be applied in engineering problems. For example, innovization consists in establishing effective rules between all the variables of the system (decision variables and objectives), from the data obtained after the run of a MOEA. This is a further step towards developing computational tools that are able to provide informed solutions to the engineer based on data analysis - they are designated as data-driven optimization methodologies. In a certain way, the latter are a form of returning to situations where only a limited quantity of data is available, since the new AI technologies allow, within some limits, to perform optimizations based on a limited amount of data, experimental or computational. This is certainly a trend that still requires further research.

Funding: This research was funded by NAWA-Narodowa Agencja Wymiany Akademickiej, under grant PPN/ULM/2020/1/00125 and European Union's Horizon 2020 research and innovation programme under the Marie Skłodowska-Curie Grant Agreement No 734205-H2020-MSCA-RISE-2016. The authors also acknowledge the funding by FEDER funds through the COMPETE 2020 Programme and National Funds through FCT (Portuguese Foundation for Science and Technology) under the projects UID-B/05256/2020, UID-P/05256/2020.

Acknowledgments: In this section, you can acknowledge any support given which is not covered by the author contribution or funding sections. This may include administrative and technical support, or donations in kind (e.g., materials used for experiments).

Conflicts of Interest: The authors declare no conflict of interest.

\section{References}

1. Tadmor, Z.; Gogos, C.G. Principles of Polymer Processing, 2nd ed.; Wiley: New York, US, 2006.

2. Agassant, J.F.; Avenas, P.; J-Ph. Sergent, J.Ph.; Carreau, P.J. Polymer Processing: Principles and Modeling, Carl Hanser Verlag: Munich, Germany, 1991.

3. Osswald, A.T.; Hernández-Ortiz, P.J. Polymer Processing: Modeling and Simulation, Carl Hanser Verlag: Munich, Germany, 2006.

4. Baird, G.D.; Collias, I.D. Polymer Processing: Principles and Design, 2nd ed., Wiley: Hoboken, US, 2014.

5. Gaspar-Cunha, A.; Covas, J.A. Sikora, J. Optimization of Polymer Processing: A Review (Part I- Extrusion). Materials 2021, under revision.

6. Deb, K. Multi-Objective Optimization using Evolutionary Algorithms, Wiley: New York, US, 2001.

7. Carlos Coello, C.; Lamont, B.G.; van Veldhuizen, A.D. Evolutionary Algorithms for Solving Multi-Objective Problems, 2nd ed.; Springer, New York, US, 2007.

8. Jin, Y.; Wang, H.; Chugh, T.; Guo, D.; Miettinen, K. Data-Driven Evolutionary Optimization: An Overview and Case Studies. IEEE Trans. Evol. Comput. 2019, 23, 442-458, doi: 10.1109/TEVC.2018.2869001. 
9. Ibañez, R.; Casteran, F.; Argerich, C.; Ghnatios, C.; Hascoet, N.; Ammar, A.; Cassagnau, P.; Chinesta, F. On the Data-Driven Modeling of Reactive Extrusion. Fluids 2020, 5, 94, doi:org/10.3390/fluids5020094.

10. Gaspar-Cunha, A.; Covas, J. A.; Sikora, J. Modelling the effect of grooved barrels on the performance of single screw extruders. In Technological and design aspects of the processing of composites and nanocomposites: Volume I, $1^{\text {st }}$ ed.; J. Sikora, L. Dulebová, Eds.; Technical University of Kosice: Kosice, Slovak Republic, 2018, pp-22-42

11. Gaspar-Cunha, A. Global Extruder Modelling: Active grooved feed section, rotational barrel segment and special screws. In Technological and design aspects of the processing of composites and nanocomposites: Volume II, 1st ed.; J. Sikora,L. Dulebova, Eds.;, Lublin University of Technology Publishing House: Lublin, Poland, 2019, pp. 97-111.

12. Majewski, Ł., Debski, H., \& Dulebová, L. New concepts of a rotational barrel segment for a new generation extruder. In Technological and design aspects of the processing of composites and nanocomposites: Volume II, $1^{\text {st }}$ ed.; J. Sikora, L. Dulebova (Eds.; . Lublin University of Technology Publishing House, Lublin, Poland, 2019, pp. 19-60

13. Gaspar-Cunha, A. Computational assessment of the rotational barrel segment located on the meetering zone of an extruder. In Technological and design aspects of the processing of composites and nanocomposites: Volume II, $1^{\text {st }}$ ed.; J. Sikora, L. Dulebová, EDS.; Lublin University of Technology Publishing House, Lublin, Poland, 2019, pp. 86-96

14. Verbraak, C.P.J.M.; Meijer, H.E.H. Screw design in injection molding. Polym. Eng. Sci. 1989, 29, 479-487, doi:10.1002/pen.760290708.

15. Huang, M.-S. Design analysis of a standard injection screw for plasticising polycarbonate resins. J. Polym. Eng. 2015, 36, 537-548, doi:10.1515/polyeng-2015-0275.

16. Wang, M.-W.; Arifin, F.; Kuo, J.-W.; Dzwo, T.-H.. Optimal Design of Plasticizing Screw Using Artificial Intelligent Approach. J. Phys. Conf. Ser. 2020, 1500, 012022, doi:10.1088/1742-6596/1500/1/012022.

17. Seow, L.; Lam, Y. Optimizing flow in plastic injection molding. J. Mater. Process. Technol. 1997, 72, 333-341, doi:10.1016/s0924-0136(97)00188-x.

18. Lee, B.H.; Kim, B.H. Optimization of Part Wall Thicknesses to Reduce Warpage of Injection-Molded Parts Based on The Modified Complex Method. Polym. Plast. Technol. Eng. 1995, 34, 793-811, doi:10.1080/03602559508009600.

19. Chang, T.C.; Faison, E. Shrinkage Behaviour and Optimization of Injection Molded Parts Studied by the Taguchi Method. Polym. Eng. Sci. 2001, 41, 703-710, doi: 10.1002/pen.10766.

20. Feng, C.; Jeffrey, K.; Su, K. Optimization of Multiple Quality Characteristics for Polyether Ether Ketone Injection Molding Process. Fibers Polym. 2006, 7, 404-413, doi:10.1007/BF02875773.

21. Tang, S.H.; Tan, Y.J.; Sapuan, S.M.; Sulaiman, S.; Ismail, N.; Samin, R. The use of Taguchi Method in the Design of Plastic Injection Mould for Reducing Warpage. J. Mat. Proc. Technol. 2007, 182, 418-426, doi:10.1016/j.jmatprotec.2006.08.025.

22. Ahmad, A.; Wahab, M.S.; Shah, A.S.M.; Kamarudin, K.; Hehsan, H. Optimization of processing parameters for plastic injection moulding process towards moulded part shrinkage. AIP Conf. Proc. 2019, 2129, 020168, doi:10.1063/1.5118176.

23. Mukras, S.M.S. Experimental-Based Optimization of Injection Molding Process Parameters for Short Product Cycle Time. Adv. Polym. Technol. 2020, 2020, 1309209, doi:10.1155/2020/1309209.

24. Chen, W.; Huang, C; Hung, C. Optimization of plastic injection molding process by dual response surface method with non-linear programming. Eng. Comput. 2010, 27, 951-966, doi:10.1108/02644401011082971.

25. Huang, W.T.; Wu, D.H.; Tasi, Z.Y.; Tsai, C. Optimization of Process Parameters in Plastic Injection Mold Simulation for Auto Lock-Parts Using Taguchi-Grey Method Based on Multi-Objective. Proceeding of the 2015 International Conference on Structural, Mechanical and Material Engineering, November 2015, 52-55, doi:10.2991/icsmme-15.2015.13.

26. Smith, D.E.; Tortorelli, D.A.; Tucker, C.L. Analysis and sensitivity analysis for polymer injection and compression molding. Comput. Meth. Appl. Mech. Eng. 1998, 167, 325-344, doi:10.1016/s0045-7825(98)00131-5.

27. Lam, Y.C.; Seow, L.W. Cavity balance for plastic injection molding. Polym. Eng. Sci. 2000, 40, 1273-1280, doi:10.1002/pen.11255.

28. Lam, Y.; Jin, S. Optimization of Gate Location for Plastic Injection Molding, J. Inject. Mold. Technol. 2001, 5, 180-192.

29. Pirc, N.; Schmidt, F.; Mongeau, M.; Bugarin, F. 3D BEM-based cooling-channel shape optimization for injection molding processes. Int. J. Simul. Multidiscip. Des. Optim. 2008, 2, 245-252, doi:10.1051/ijsmdo:2008033.

30. Zhai, M.; Lam, Y.C.; Au, C.K. Algorithms for Two Gate Optimization in Injection Molding. Int. Polym. Process. 2005, 20, 1418, doi:10.3139/217.1860.

31. Qiao, H. A Systematic Computer-Aided Approach to Cooling System Optimal Design in Plastic Injection Molding. Intern. J. Mech. Sci. 2006, 48, 430-439, doi:10.1016/j.ijmecsci.2005.11.001.

32. Li, J.; Li, D.; Guo, Z.; LV, H. Single Gate Optimization for Plastic Injection Mold. J. of Zhejiang University Science A 2007, 8 , 1077-1083, doi:10.1631/jzus.2007.A1077.

33. Ye, H.; Wang, K.K. Optimization of Injection-Molding Process with Genetic Algorithms. Proceedings of SPE Annual Technical Conference, New York, US, 2-6 May 1999, 594-599.

34. Shi, F.; Lou, Z.L.; Lu, J.G.; Zhang, Y.Q. Optimisation of Plastic Injection Moulding Process with Soft Computing. Int. J. Adv. Manuf. Technol. 2003, 21, 656-661, doi:10.1007/s00170-002-1374-3.

35. Lam, Y.C.; Zhai, L.Y.; Tai, K.; Fok, S.C. An Evolutionary Approach for Cooling System Optimization in Plastic Injection Molding. Int. J. of Prod. Res. 2004, 42, 2047-2061, doi:10.1080/00207540310001622412.

36. Kurtaran, H.; Ozcelik, B.; Erzurumlu, T. Warpage Optimization of a Bus Ceiling Lamp Base using Neural Network Model and Genetic Algorithm. J. of Mat. Proc. Technol. 2005, 169, 314-319, doi:10.1016/j.jmatprotec.2005.03.013. 
37. Ozcelik, B.; Erzurumlu, T. Determination of Effecting Dimensional Parameters on Warpage of Thin Shell Plastic Parts using Integrated Response Surface Method and Genetic Algorithm. Int. Comm. in Heat and Mass Transfer 2005, 32, 1085-1094, doi:0.1016/j.icheatmasstransfer.2004.10.032.

38. Ozcelik, B.; Erzurumlu, T. Comparison of the Warpage Optimization in the Plastic Injection Molding using ANOVA, Neural Network Model and Genetic Algorithm. J. Mat. Process. Technol. 2006, 171, 437-445 doi:10.1016/j.jmatprotec.2005.04.120.

39. $\mathrm{Wu}, \mathrm{C}$; $\mathrm{Ku}, \mathrm{C}$; Pai, H. Injection Molding Optimization with Weld Line Design Constraint using Distributed Multi-population Genetic Algorithm. Int. J. Adv. Manuf. Technol. 2011, 52, 131-141, doi:10.1007/s00170-010-2719-y.

40. Iniesta, A.; Alcaraz, G; Jorge L.; ManuelIván, R.B. Optimization of injection molding process parameters by a hybrid of artificial neural network and artificial bee colony algorithm. Revista Facultad de Ingeniería Universidad de Antioquia 2013, 67, 43-51, http://www.scielo.org.co/scielo.php?script=sci_arttext\&pid=S0120-62302013000200004\&lng=en\&tlng=en.

41. Changyu, S.; Lixia, W.; Qian, L. Optimization of Injection Molding Process Parameters using Combination of Artificial Neural Network and Genetic Algorithm Method. J. Mat. Process. Technol. 2007, 183, 412-418, doi:10.1016/j.jmatprotec.2006.10.036.

42. Singh, G.; Pradhan, M.K.; Verma, A. Multi Response optimization of injection moulding Process parameters to reduce cycle time and warpage. Mater. Today 2018, 5, 8398-8405, doi:10.1016/j.matpr.2017.11.534.

43. Sreedharan, J.; Jeevanantham, A.; Rajeshkannan, A. Multi-objective optimization for multi-stage sequential plastic injection molding with plating process using RSM and PCA-based weighted-GRA. Proceedings of the Institution of Mechanical Engineers, Part C: J. Mech. Eng. Sci. 2019, doi:10.1177/0954406219887993.

44. Kumar, B.P.; Venkataramaiah, P.; Ganesh, J.S. Optimization Of Process Parameters In Injection Moulding Of A Polymer Composite Product By Using Gra. Mater. Today 2019, 18, 4637-4647, doi:10.1016/j.matpr.2019.07.448.

45. Kitayama, S.; Miyakawa, H.; Takano, M. et al. Multi-objective optimization of injection molding process parameters for short cycle time and warpage reduction using conformal cooling channel. Int. J. Adv. Manuf. Technol. 2017, 88, 1735-1744, doi:10.1007/s00170-016-8904-x.

46. Kitayama, S.; Tamada, K.; Takano, M.; Aiba, S. Numerical optimization of process parameters in plastic injection molding for minimizing weldlines and clamping force using conformal cooling channel. J. Manuf. Process 2018, 32, 782-790, doi:10.1016/j.jmapro.2018.04.007.

47. Moayyedian, M.; Mamedov, A. Multi-Objective Optimization of Injection Molding Process for Determination of Feasible Moldability Index. Procedia CIRP 2019, 84, 769-773, doi:10.1016/j.procir.2019.04.213.

48. Tang, L.Q.; Chassapis, C.; Manoochehri, S. Optimal cooling system design for multi-cavity injection molding. Finite Elem. Anal. Des. 1997, 26, 229-251, doi:10.1016/s0168-874x(96)00083-2.

49. Park, S.J.; Kwon, T.H. Optimal cooling system design for the injection molding process. Polym. Eng. Sci. 1998, 38, 1450-1462, doi:10.1002/pen.10316.

50. Huang, J.; Fadel, G.M. Bi-Objective Optimization Design of Heterogeneous Injection Mold Cooling Systems. J. Mech. Des. 2001, 123, 226-239, doi:10.1115/1.1347992.

51. Shen, C.-Y.; Yu, X.-R.; Li, Q.; Li, H.-M. Gate Location Optimization in Injection Molding By Using Modified Hill-Climbing Algorithm. Polym. Plast. Technol. Eng. 2004, 43, 649-659, doi:10.1081/ppt-120038056.

52. Mathey, E.; Penazzi, L.; Schmidt, F.M.; Rondé-Oustau, F. Automatic Optimization of the Cooling of Injection Mold based on the Boundary Element Method. Proceedings of the 8th International conference on numerical methods in industrial forming processes, Columbus, US, Jun 2004, 712, 222-227.

53. Agazzi, A.; Sobotka, V.; Le Goff, R.; Garcia, D.; Jarny, Y. A Methodology for the Design of Effective Cooling System in Injection Moulding. Int. J. Mater. Form. 2010, 3, 13-16, doi:10.1007/s12289-010-0695-2.

54. Shie, J.R. Optimization of Injection-Molding Process for Mechanical Properties of Polypropylene Components via a Generalized Regression Neural Network. Polym. Adv. Technol. 2008, 19, 7383, doi:10.1002/pat.976.

55. Pandelidis, I.; Zou, Q. Optimization of Injection Molding Design. Part I: Gate Location Optimization. Polym. Eng. Sci. 1990, 30, 873-882, doi:10.1002/pen.760301502.

56. Pandelidis, I.; Zou, Q. Optimization of Injection Molding Design. Part II: Molding Conditions Optimization. Polym. Eng. Sci. 1990, 30, 883-892, doi:10.1002/pen.760301503.

57. Turng, L.-S.; Peić, M. Computer aided process and design optimization for injection moulding. Proceedings of the Institution of Mechanical Engineers, Part B: Journal of Engineering Manufacture 2002, 216, 1523-1532, doi:10.1243/095440502321016288.

58. Lam, Y.C.; Deng, Y.M.; Au, C.K. A GA/Gradient Hybrid Approach for Injection Molding Conditions Optimisation. Eng. Comp. 2006, 21, 193-202, doi:10.1007/s00366-005-0004-8.

59. Kim, S.J.; Lee, K.; Kim, Y.I. Optimization of Injection-Molding Conditions using Genetic Algorithm. Proceedings of the 4th Intern. Conf. on Computer Aided Design and Computer Graphics 1996, 2644, 173-180, doi:10.1117/12.235515.

60. Chen, W.C.; Fu, G.L.; Tai, P.H.; Deng, W.J. Process Parameter Optimization for MIMO Plastic Injection Molding via Soft Computing. Exp. Sys. App. 2007, 36, 1114-1122, doi:10.1016/j.eswa.2007.10.020.

61. Meiabadi, M.; Vafaei, A.; Sharifi, F. Optimization of Plastic Injection Molding Process by Combination of Artificial Neural Network and Genetic Algorithm. J. Optim. Ind. Eng. 2013, 6, 49-54.

62. Mok, S.L.; Kwong, C.K.; Lau, W.S. A Hybrid Neural Network and Genetic Algorithm Approach to the Determination of Initial Process Parameters for Injection Moulding. Int. J. Adv. Manuf. Technol. 2001, 18, 404-409, doi:10.1007/s001700170050. 
63. Alam, K.; Kamal, M.R. A Genetic Optimization of Shrinkage by Runner Balancing. Proceedings of SPE Annual Technical Conference, Nashville, Tennessee, US, 4-8 May 2003, 639-641.

64. Alam, K.; Kamal, M.R. Runner Balancing by a Direct Genetic Optimization of Shrinkage. Polym. Eng. Sci. 2004, 44, 19491959, doi:10.1002/pen.20198.

65. Alam, K.; Kamal, M.R. A Robust Optimization of Injection Molding Runner Balancing. Comp. Chem. Eng. 2005, 29, 19341944, doi:10.1016/j.compchemeng.2005.04.005.

66. Gaspar-Cunha, A.; Viana, J. Using Multi-Objective Evolutionary Algorithms to Optimize Mechanical Properties of Injection Molded Part. Int. Polym. Process. 2005, 20, 274-285, doi:10.3139/217.1889.

67. Castro, C.; Ríos, M.C.; Castro, J.M.; Lilly B. Multiple criteria optimization with variability considerations in injection molding. Polym. Eng. Sci. 2007, 47, 400-409, doi:10.1002/pen.20639.

68. Fernandes, C.; Pontes; A.J.; Viana, J.C.; Gaspar-Cunha, A. Using Multiobjective Evolutionary Algorithms in the Optimization of Operating Conditions of Polymer Injection Molding. Polym. Eng. Sci. 2010, 50, 1667-1678.

69. Fernandes, C.; Pontes, A.J.; Viana, J.C.; Gaspar-Cunha, A. Using Multi-objective Evolutionary Algorithms for Optimization of the Cooling System in Polymer Injection Molding. Int. Polym. Proc. 2012, 27, 213-223, doi:10.3139/217.2511.

70. Xu, G.; Yang, Z.; Long, G. Multi-objective optimization of MIMO plastic injection molding process conditions based on particle swarm optimization. Int. J. Adv. Manuf. Technol. 2012, 58, 521-531, doi:10.1007/s00170-011-3425-0.

71. Tahboub, K.; Rawabdeh, I. A design of experiments approach for optimizing an extrusion blow molding process. J. Qual. Maint. Eng. 2004, 10, 47-54, doi:10.1108/13552510410526866.

72. Agrawal, V.; Vimal, J.; Chaturvedi, V. Optimisation of extrusion blow molding process parameters using grey relational analysis and taguchi. Int. J. Res. Eng. App. Sci. 2012, 2, 407-417.

73. Dohare, J.; Chaturvedi, V.; Vimal, J. Investigation of Optimal Process Parameters of Extrusion Blow Molding Process Using Grey Taguchi Analysis. Int. J. Manuf. Mater. Process. 2018, 4, 1, doi:10.37628/ijmmp.v4i1.615.

74. DiRaddo, R.W.; Garcia-Rejon, A. Profile optimization for the prediction of initial parison dimensions from final blow moulded part specifications. Comput. Chem. Eng. 1993, 17, 751-764, doi:10.1016/0098-1354(93)80061-q.

75. Thibault, F.; Chantal, G.; Laroche, D.; Diraddo, R. Development of an MDO Software Environment for the Blow Moulding Proceedings of the 6th International Conference on Computer Supported Cooperative Work Design (CSCWD), London, Ontario, Canada, 12-14 July 2001.

76. Gauvin, C.; Thibault, F.; Laroche, D. Optimization of blow molded part performance through process simulation. Polym. Eng. Sci. 2003, 43, 1407-1414, doi:10.1002/pen.10119.

77. Yu, J.-Ch.; Hung, T.-R.; Juang, J.-Y. Thibault, F. Design Optimization Using Soft Computing Techniques For Extrusion Blow Molding Processes. NSC-NRC Taiwan-Canada Joint Workshop on Advanced Manufacturing, London, Ontario, Canada 2002, 23-24 September 2002.

78. Yu, J.-Ch.; Chen, X.-X.; Hung, T.-R.; Thibault, F. Optimization of Extrusion Blow Molding Processes using Soft Computing and Taguchi's Method. J. Intell. Manuf. 2004, 15, 625-634.

79. Hsu, Y.-L. Liu, T.-Ch.; Thibault, F.; Lanctot, B. Design optimization of the blow moulding process using a fuzzy optimization algorithm. Proceedings of the Institution of Mechanical Engineers Part B J. Eng. Manuf. 2004, 218, 197-212.

80. Yu, J.-Ch..; Juang, J.-Y. Design Optimization of Extrusion-Blow-Molded Parts Using Prediction-Reliability-Guided Search of Evolving Network Modeling. J. App. Polym. Sci. 2010, 117, 222-234, doi:10.1002/app.31954.

81. Huang, G.-Q.; Huang, H.-X. Optimizing parison thickness for extrusion blow molding by hybrid method. J. Mater. Process. Technol. 2007, 182, 512-518.

82. Hopmann, Ch.; Rasche, S.; Windeck, Ch. Simulative design and process optimization of the two-stage stretch-blow molding process. PROCEEDINGS OF PPS-30: Proceedings of the 30th International Conference of the Polymer Processing Society 2015, 1664. 050011. 10.1063/1.4918415.

83. Bordival, M.; Schmidt, F.M.; Maoult, Y.L.; Velay, V. Optimization of preform temperature distribution for the stretch-blow molding of PET bottles: infrared heating and blowing modeling. Polym. Eng. Sci. 2009, 49, 783-793, doi:10.1002/pen.21296.

84. Biglione, J. Simulation et Optimisation du Procédé d'Injection Souflage Cycle Chaud. Modélisation et simulation. PhD Thesis, INSA Lyon, France 2015.

85. Biglione, Y.; Béreaux, J.-Y.; Charmeau, J.B.; Chhay, S. Numerical simulation and optimization of the injection blow molding of polypropylene bottles-a single stage process. Int. J. Mater. Form. 2016, 9, 471-487, doi:10.1007/s12289-015-1234-y.

86. Demirel, D.Optimisation of mould surface temperature and bottle residence time in mould for the carbonated soft drink PET containers. Polym. Test. 2017, 60, 220-228, doi:10.1016/j.polymertesting.2017.03.030.

87. Lee, D.K.; Soh, S.K. Prediction of optimal preform thickness distribution in blow molding. Polym. Eng. Sci. 1996, 36, 15131520, doi:10.1002/pen.10546.

88. Thibault, F.; Malo, A.; Lanctot, B. Diraddo, R. Preform Shape and Operating Condition Optimization for the Stretch Blow Molding Process. Polym. Eng. Sci. 2007, 47, 289-301, doi:10.1002/pen.20707.

89. Denysiuk, R.,F.; Duarte, P.N.; Gaspar-Cunha, A. Evolving Neural Networks to Optimize Material Usage in Blow Molded Containers. EUROGEN 2017. Madrid. Spain, Springer Berlin/Heidelberg.

90. Denysiuk, R.; Gonçalves N.; Pinto, R.; Silva, H.; Duarte, F.; Nunes, J.; Gaspar-Cunha, A. Optimization of Injection Stretch Blow Molding: Part I - Defining Part Thickness Profile. Int. Polym. Process. 2019, 34, 314-323, doi:10.3139/217.3746. 
91. Pinto, R.; Hugo S.; Duarte, F.; Nunes, J.; Gaspar-Cunha, A. Neuroevolutionary Multiobjective Methodology for the Optimization of the Injection Blow Molding Process. Proceedings of the Evolutionary Multi-Criterion Optimization - 10th International Conference, EMO 2019. East Lansing, Michigan, US, 10-13 March 2019, 743-754.

92. Pinto, R.S.; Hugo, M.S.; Duarte, F.M.; Nunes, J.P; Gaspar-Cunha, A. Neuroevolutionary Multiobjective Optimization of Injection Stretch Blow Molding Process in the Blowing Phase. Comput. Meth. Appl. Scie. 2021, 55, 307-318.

93. Duarte, F.M.; Covas, J.A. Heating Thermoplastic Sheets for Thermoforming: Solution to the Direct and Inverse Problems, Plast., Rubb. Comp. Proc. \& Appl. 1997, $26,213$.

94. Duarte, F. M.; Covas, J. A. IR sheet heating in roll fed thermoforming: Part 1 - Solving direct and inverse heating problems. Plastics, Rubber and Composites. 2002, 31(7), 307-317. doi:10.1179/146580102225006530

95. Wang, C.; Nied, H.F. Temperature Optimization for Improved Thickness Control in Thermoforming. J. Mater. Process. Manuf. Sci. 1999, 8, 113-126.

96. Bordival, M.; Andrieu, S.; Schmidt, F.; Maoult Y.L.; Monteix, S. Optimization of infrared heating system for the thermoforming process. Proceedings of the 8th ESAFORM conference on material forming ESAFORM 2005, Cluj-Napoca, Romania, 27-29 April 2005, 925-928, hal-01788422.

97. Chy M. M.; Boulet B. A Conjugate Gradient Method for the Solution of the Inverse Heating Problem in Thermoforming. Proceedings of IEEE Industry Applications Society Annual Meeting, Houston, TX, US, 3-7 October 2010, 1-8.

98. Chy M. M.; Boulet B.; Haidar A. A model predictive controller of plastic sheet temperature for a thermoforming process. Proceedings of the 2011 American Control Conference, San Francisco, CA, USA, 29 June-1 July 2011, 4410-4415.

99. Li, Z.; Heo, K.; Seol, S. Time-dependent Optimal Heater Control in Thermoforming Preheating Using Dual Optimization Steps. Int. J. Pr. Eng. Manuf. 2008, 9, 51-56.

100. Li, Z.; Ma, G.; Xuan, D.; Seol S.; Shen Y. A study on control of heater power and heating time for thermoforming. Int. J. Pr.. Eng. Manuf. 2010, 11, 873-878.

101. Erchiqui, F.; Nahas, N.; Nourelfath, M.; Souli, M. Metaheuristic algorithms for optimisation of infrared heating in thermoforming process. Int. J. Metaheuristics 2011, 1, 199-221, doi:10.1504/ijmheur.2011.041194.

102. Bachir, Ch.K.; Rebaine, D.; Erchiqui, F.; Fofana, I. Metaheuristics as a Solving Approach for the Infrared Heating in the Thermoforming Process. GERAD-G-2015-139, Montreal, Canada 2015.

103. Erchiqui, F. Application of genetic and simulated annealing algorithms for optimization of infrared heating stage in thermoforming process. Appl. Therm. Eng. 2018, 128, 1263-1272.

104. Bachir, Ch.K.; Rebaine, D.; Erchiqui, F.; Fofana, I.; Nahas, N. Numerically Optimizing the Distribution of the Infrared Radiative Energy on a Surface of a Thermoplastic Sheet Surface. J. Heat Transf. 2018, 140, 102101, doi:10.1115/1.4039990.

105. Kahina Bachir-Cherif, Optimisation de l'étape de chauage infrarouge en thermoformage à l'aide de méta-heuristiques, PhD Thesis, Université du Québeque à Chicoutimi, 2019.

106. Yang, C.; Hung, S.-W. Modeling and Optimization of a Plastic Thermoforming Process. J. Reinf. Plast. Compos. 2004, 23, 109121, doi: $10.1177 / 0731684404029324$.

107. Chang, Y.-Z.; Wen, T.-T.; Liu, S.-J. Derivation of optimal processing parameters of polypropylene foam thermoforming by an artificial neural network. Polym. Eng. Sci. 2005, 45, 375-384, doi: 10.1002/pen.20287.

108. Leite, W. O.; Campos Rubio, J. C.; Mata Cabrera, F.; Carrasco, A.; Hanafi, I. Vacuum Thermoforming Process: An Approach to Modeling and Optimization Using Artificial Neural Networks. Polymers 2018, 10, 143, doi:10.3390/polym10020143.

109. Leite, W.; Rubio, J.; Mata,F.; Hanafi,I.; Carrasco,A. Dimensional and Geometrical Errors in Vacuum Thermoforming Products: An Approach to Modeling and Optimization by Multiple Response Optimization. Meas. Sci. Rev. 2018, 18, 113-122.

110. Sasimowski, E. The use of utility function for optimization of thermoforming. Polimery 2018, 63, 807-814, doi:10.14314/polimery.2018.11.9.

111. Gaspar-Cunha, A.; Costa, P.; Galuppo, W.d.C.; Nóbrega, J.M.; Duarte, F.; Costa, L. Multi-Objective Optimization of Plastics Thermoforming. Mathematics 2021, 9, 1760. https://doi.org/10.3390/math9151760 